
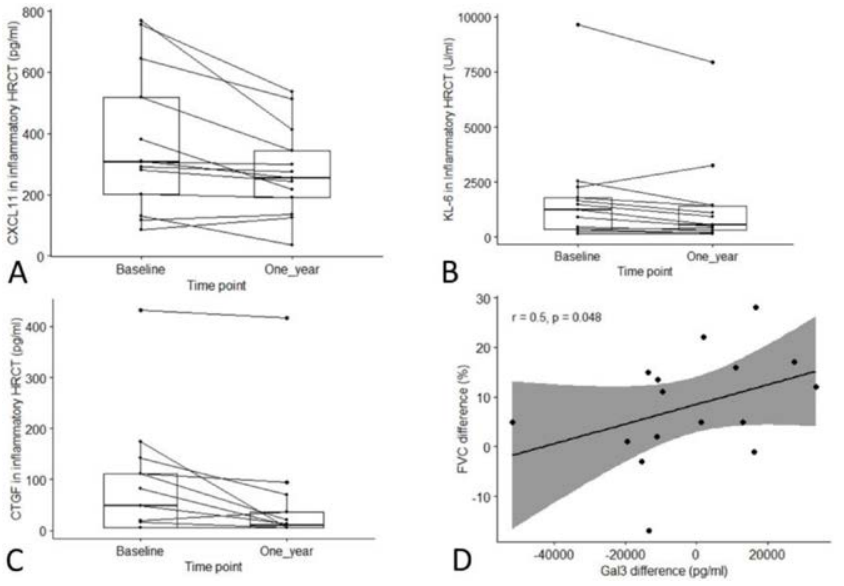

Figure 1.

Acknowledgements: We want to thank the Utrecht Immunity and Infection cohort for providing the serum samples, Marieke Vianen for the support in data management and Annemieke Sloeserwij for her help in collecting the samples. We want to thank Henk Ruven from St. Antonius Hospital Utrecht for measuring Krebs von den Lungen 6, and surfactant protein D. We acknowledge Boehringer Ingelheim B.V. the Netherlands for providing financial support for this study. Disclosure of Interests: None declared DOI: 10.1136/annrheumdis-2021-eular.157

\section{AB0813 DEVELOPING SARCOPENIA IS A RISK FACTOR FOR FRACTURES IN PATIENTS WITH RHEUMATOID ARTHRITIS: 4-YEAR DATA FROM THE CHIKARA STUDY}

Y. Yamada ${ }^{1}$, M. Tada ${ }^{2}$, K. Mandai ${ }^{3}$, N. Hidaka ${ }^{2}$, H. Nakamura ${ }^{1} .{ }^{1}$ Osaka City University Graduate School of Medicine, Department of Orthopedic Surgery, Osaka City, Japan; ${ }^{2}$ Osaka City General Hospital, Department of Orthopedic Surgery, Osaka City, Japan; ${ }^{3}$ Saiseikai Nakatsu Hospital, Department of Orthopedic Surgery, Osaka City, Japan

Background: Patients with rheumatoid arthritis (RA) tend to have sarcopenia due to decreased muscle mass and function. We previously reported that $13.2 \%$ of RA patients without sarcopenia at baseline developed sarcopenia over a year using data from the prospective, observational CHIKARA study1.

Table 1. Characteristics of 77 RA patients by sarcopenia status at baseline and at 4-year follow-up.

\begin{tabular}{|c|c|c|c|c|c|}
\hline & $\begin{array}{c}\text { no } \\
\text { development } \\
(n=48)\end{array}$ & $\begin{array}{c}\text { development } \\
(\mathrm{n}=6)\end{array}$ & $\begin{array}{l}\text { cured } \\
(n=10)\end{array}$ & $\begin{array}{l}\text { persisted } \\
(n=13)\end{array}$ & $\begin{array}{c}\mathrm{p} \\
\text { value }\end{array}$ \\
\hline \multicolumn{6}{|l|}{ Baseline } \\
\hline age, years & $64.5(57.8,72)$ & $\begin{array}{c}70.0(65.5 \\
72.3)\end{array}$ & $\begin{array}{c}61.0 \\
(54.5,68.3)\end{array}$ & $72(68,81)$ & 0.062 \\
\hline $\begin{array}{l}\text { disease duration, } \\
\text { years }\end{array}$ & $\begin{array}{c}4.6 \\
(1.1,9.9)\end{array}$ & $\begin{array}{c}11.7 \\
(2.8,18.9)\end{array}$ & $\begin{array}{c}8.1 \\
(4.2,14.3)\end{array}$ & $4.0(2.2,7.7)$ & 0.427 \\
\hline biologics use, \% & 37.5 & 16.7 & 30.0 & 23.1 & 0.617 \\
\hline GC use, $\%$ & 27.1 & 16.7 & 10.0 & 23.1 & 0.678 \\
\hline MMP-3, ng/ml & $\begin{array}{c}66.8 \\
(51.8,103)\end{array}$ & $\begin{array}{c}52.5 \\
(40.0,56.7)\end{array}$ & $\begin{array}{c}82.8 \\
(57.8,186)\end{array}$ & $\begin{array}{c}157.5 \\
(90.8,250)\end{array}$ & 0.001 \\
\hline DAS28ESR & $3.43 \pm 0.87$ & $3.48 \pm 1.32$ & $3.36 \pm 1.08$ & $3.80 \pm 1.27$ & 0.661 \\
\hline $\mathrm{mHAQ}$ & $\begin{array}{c}0.31 \\
(0,0.50)\end{array}$ & $\begin{array}{c}0.19 \\
(0.03,0.44)\end{array}$ & $\begin{array}{c}0.38 \\
(0,0.84)\end{array}$ & $\begin{array}{l}0.50(0.25 \\
0.88)\end{array}$ & 0.383 \\
\hline $\mathrm{BMI}, \mathrm{kg} / \mathrm{m}^{2}$ & $23.4 \pm 3.6$ & $21.6 \pm 2.4$ & $19.2 \pm 1.6$ & $19.5 \pm 2.6$ & $<0.001$ \\
\hline $\mathrm{SMI}, \mathrm{kg} / \mathrm{m}^{2}$ & $6.8 \pm 0.8$ & $6.2 \pm 0.6$ & $5.8 \pm 0.5$ & $5.7 \pm 0.6$ & $<0.001$ \\
\hline fat percentage, $\%$ & $30.4 \pm 8.4$ & $29.1 \pm 9.1$ & $23.9 \pm 4.0$ & $25.1 \pm 8.3$ & 0.046 \\
\hline $\begin{array}{l}\text { estimated bone } \\
\text { mass, kg }\end{array}$ & $2.2(2.0,2.4)$ & $1.9(1.8,2.1)$ & $2.0(1.7,2.1)$ & $1.7(1.7,1.9)$ & 0.012 \\
\hline BMR, kcal & $\begin{array}{c}1100 \\
(1031,1197)\end{array}$ & $\begin{array}{c}1029 \\
(918,1070)\end{array}$ & $\begin{array}{c}1012 \\
(917,1057)\end{array}$ & $\begin{array}{c}934 \\
(894,1006)\end{array}$ & 0.005 \\
\hline \multicolumn{6}{|c|}{ Change during 4 years } \\
\hline$\triangle \mathrm{DAS} 28 \mathrm{ESR}$ & $-0.34 \pm 0.97$ & $-0.52 \pm 0.98$ & $-0.60 \pm 1.46$ & $-0.56 \pm 1.14$ & 0.834 \\
\hline$\triangle \mathrm{mHAQ}$ & $0(-0.25,0.16)$ & $0.19(0,0.56)$ & $-0.06(-0.44,0.94)$ & $0(-0.38,0.38)$ & 0.357 \\
\hline$\Delta \mathrm{SMI}, \mathrm{kg} / \mathrm{m}^{2}$ & $0.0 \pm 0.3$ & $-0.6 \pm 0.3$ & $0.3 \pm 0.4$ & $-0.0 \pm 0.3$ & $<0.001$ \\
\hline fall, \% & 43.8 & 83.3 & 30.0 & 23.1 & 0.079 \\
\hline fracture, \% & 14.6 & 83.3 & 20.0 & 23.1 & 0.002 \\
\hline
\end{tabular}

Data are shown as mean \pm standard deviation (SD) or median (25th, 75 th percentile).GC: glucocorticoids, BMI: body mass index, SMI: skeletal muscle mass index, BMR: body metabolization rate.
Objectives: The aim was to investigate sarcopenia status and the characteristics of RA patients longitudinally.

Methods: Body composition, laboratory data, disease activity, physical function, treatment, and history of falls and fractures were investigated in 100 RA patients who participated in the CHIKARA study at baseline and at 4 years. The patients were divided into 4 groups depending on their sarcopenia status: no sarcopenia development (N group), sarcopenia development (S group), cured (C group), and persisted ( $\mathrm{P}$ group)

Results: Of the 77 RA patients who completed the survey, 48 were in the $\mathrm{N}$ group; their body mass index, skeletal muscle mass index, fat percentage, estimated bone mass, and body metabolization rate at baseline were significantly elevated. On the other hand, 6 patients were in the S group; $83.3 \%$ of them experienced fractures during the 4 years, significantly more than in the other groups. Ten patients were in the P group, and their baseline MMP-3 was significantly higher than in the other groups. Thirteen patients were in the $\mathrm{C}$ group. There were no differences among the 4 groups in disease activity and physical function (Table 1).

Conclusion: Overall, $7.8 \%$ of RA patients developed sarcopenia during the 4-year follow-up period, and they developed fractures more frequently. Evaluation of sarcopenia is important for risk assessment of fractures.

\section{REFERENCES:}

[1] Y Yamada, M Tada, K Mandai et al. Glucocorticoid use is an independent risk factor for developing sarcopenia in patients with rheumatoid arthritis: from the CHIKARA study. Clin Rheumatol 2020 Jun;39(6):1757-1764.

Disclosure of Interests: Yutaro Yamada: None declared, Masahiro Tada: None declared, Koji Mandai: None declared, Noriaki Hidaka: None declared, Hiroaki Nakamura Grant/research support from: Astellas and Asahi Kasei DOI: 10.1136/annrheumdis-2021-eular.277

\section{\begin{tabular}{|l|l}
\hline AB0814 & PREGNANCY COURSE ASSESSMENT IN PATIENTS
\end{tabular} WITH RHEUMATIC DISEASES COMPARED TO CONTROLS}

O. Hamdi ${ }^{1}$, M. Sellami ${ }^{1}$, M. Yasmine ${ }^{1}$, A. Fazaa ${ }^{1}$, S. Miladi ${ }^{1}$, L. Souabni ${ }^{1}$ K. Ouenniche ${ }^{1}$, S. Kassab ${ }^{1}$, S. Chekili ${ }^{1}$, K. Ben Abdelghani ${ }^{1}$, A. Laatar ${ }^{1}$. ${ }^{1}$ Mongi Slim Hospital, Rheumatology, Tunisia, Tunisia

Background: Rheumatic diseases such as rheumatoid arthritis (RA) and spondyloarthritis (SA) may occur among women of childbearing age. Adverse events during pregnancy including disease flare, preterm delivery, and neonatal or fetal death have been reported.

Objectives: Our aim was to assess the impact of rheumatic diseases on the course of pregnancy.

Methods: We conducted a cross-sectional study involving patients with RA (2010 ACR/EULAR criteria) and SA (2009 ASAS criteria) (study group) as well as healthy controls (control group) matched by age and gender. All women included had at least one pregnancy. Data were collected through telephonic interviews. We used the Student $t$ test to compare the study group and the control group. Results: We enrolled 57 patients ( 30 RA and 27 SA) and 57 controls. The mean age in the study and the control groups were respectively $43.2 \pm 8.2$ years [2648] and $37.5 \pm 6$ years. The mean chronic inflammatory rheumatisms duration was $13.81 \pm 6.2$ years. A history of primary sterility was found in 3 patients ( 1 $\mathrm{RA}$ and $2 \mathrm{SA}$ ) and none in the control group. The mean age during the first pregnancy was significantly higher in the study group ( $28 \pm 6.2$ years versus $24 \pm 7$ years in the control group) $(p=0.01)$. Eight patients (5 RA and $3 S A$ ) had a history of spontaneous miscarriage. A terminated pregnancy was noted in 3 patients ( $1 \mathrm{RA}$ and $2 \mathrm{SA}$ ). Complications during pregnancy in the study group were gestational diabetes $(0.3 \%)$, premature delivery $(0.3)$, premature rupture of membranes $(0.3 \%)$, abortion threat $(0.3 \%)$ and pre-eclampsia $(6 \%)$ Pregnancy was more associated with complications in the study group $(p=0.05)$. Cesarean section was more used in the study group (28 patients versus 9 in the control group; $p=0.00)$. The main indications of cesarean section in the study group were macrosomia (11 patients), scar uterus (6 patients), sacroiliitis (4 SA patients), twin pregnancy (2 patients), and undetermined reasons (6 patients). Fetal presentation in the study group was the seat presentation $(3 \%)$, top presentation ( $4 \%)$, face $(2 \%)$, and forehead presentation $(0.3 \%)$ with no significant difference with the control group. Complications of childbirth in the study group were hemorrhage of delivery $(10.3 \%)$, cord widening $(6.6 \%)$, perinatal asphyxia $(4.9 \%)$, and dystocia (1.9\%). However, no statistically significant differences were found between the two groups in the prevalence of complications of childbirth. During pregnancy, 5 patients were on salazopyrine, 2 on corticosteroids and, 1 on non-steroidal anti-inflammatories.

Conclusion: Our study showed that pregnancies with rheumatic diseases were at increased risk of having maternal complications and adverse neonatal outcomes. 